\title{
ARTÍCULOS
}

\section{DIARIO DE LA DESAPARICIÓN MEXICANA. ENTRE EL PRECEDENTE Y EL EXCESO}

\author{
DIARY OF MEXICAN DISAPPEARANCE. BETWEEN PRECEDENT AND EXCESS
}

\author{
Gabriel Gatti ${ }^{1}$ \\ Ignacio Irazuzta ${ }^{2}$ \\ Tecnologico de Monterrey
}

Universidad del País Vasco/Euskal Herriko Unibertsitatea

Recibido: 12 de noviembre de 2018; Aprobado: 19 de febrero de 2019; Publicado online: 27 de noviembre de 2019

Cómo citar este artículo / Citation: Gatti, Gabriel e Ignacio Irazuzta. 2019. «Diario de la desaparición mexicana. Entre el precedente y el exceso». Disparidades. Revista de Antropología 74(2): e019. doi: <https://doi.org/10.3989/dra.2019.02.019>.

RESUMEN: Desde las experiencias del Cono Sur latinoamericano de los años setenta, la categoría de desaparición se ha consolidado como tipo jurídico en el derecho internacional y ha circulado transnacionalmente recalando en varios contextos locales de violencia diferentes a aquellos en los que surgió. En México lo hizo con un ímpetu notable a partir de la llamada Guerra contra el Narcotráfico. A partir de entonces, y sobre aquel precedente de consolidación internacional, acuden a esa categoría una amplia variedad de víctimas que esa guerra genera; también una notable cantidad de saberes y profesiones. Pero, en su definición institucionalizada como desaparición forzada, la categoría no alcanza para dar cuenta de las nuevas situaciones de desaparición, pues no todos los casos entran en el tipo de la desaparición forzada. Entre aquel precedente y este exceso, el artículo aborda la cuestión de la desaparición en el México contemporáneo, un fenómeno todavía efervescente, realmente muy activo. Lo hace sobre los propios materiales que el trabajo de campo ha generado y está generando ahora, dando forma a una etnografía $a$ cuatro manos que recorre distintos escenarios del país donde la desaparición se está (re)definiendo.

PALABRAS CLAVE: Desaparición forzada; México; Categoría; Etnografía; Derecho humanitario internacional.

ABSTRACT: Since events in Latin America's Southern Cone in the 1970s, the label disappearance has become a consolidated category in international law and is circulated on the international stage in various localized patterns of violence that differ from those in which it originally arose. In Mexico, it gained remarkable momentum as a result of the so-called War on Drug-trafficking. Since then, and based on that precedent of international consolidation, a wide variety of victims caused by this war have been allocated to this category, and, in the meantime, a great deal of professional experience and know-how has been generated. However, the institutionalized definition of enforced disappearance is too limited to account for new emerging cases, since not all of them fall into this category. Between this precedent and the current excesses, the article deals with the question of disappearance in contemporary Mexico, where the phenomenon is alive and kicking. The paper resorts to materials generated by fieldwork, shaping a four-handed ethnography which explores different scenarios where disappearance is (re)defining itself in the Mexican context.

KEYWORDS: Enforced Disappearance; Mexico; Category; Ethnography; International Humanitarian Law.

Copyright: (C) 2019 CSIC. Este es un artículo de acceso abierto distribuido bajo los términos de la licencia de uso y distribución Creative Commons Reconocimiento 4.0 Internacional (CC BY 4.0).

1 Correo electrónico: g.gatti@ehu.es. ORCID iD: <https://orcid.org/0000-0002-0435-5074>.

2 Correo electrónico: ignacio.irazuzta@itesm.mx. ORCID iD: <https://orcid.org/0000-0001-8227-9946>. 


\section{APROXIMACIONES A UN CAMPO EN CONSTITUCIÓN}

En materia de desapariciones, México es hoy la desmesura. Las hubo en los años setenta de las que responden a un cierto modelo ya muy asentado, el de la desaparición que adjetivamos como forzada, ese que dibuja la Convención Internacional para la Protección de todas las Personas contra las Desapariciones Forzadas (de aquí en adelante, Convención) de 2006, cuando quien hace desaparecer es el Estado o fuerzas paraestatales, cuando quien desaparece es un ciudadano, cuando eso ocurre en el contexto de un Estado de derecho. Pero de entonces a esta parte no solo ha habido más de esas, sino otras muchas, realmente muchas, algunas incluso que nunca fueron llamadas de modo alguno. En México la nómina de nombres para eso es ancha y larga: levantados, encajuelados, muertos en ácido, descabezados, tratadas, asesinadas, despedazadas...

Así es, desde que arrancó la que Felipe Calderón, presidente entre 2006 y 2012, bautizó como Guerra contra el Narcotráfico llama la atención no solo la profusión y dimensión de los horrores, sino también las muchas modalidades de terror que se despliegan en México. En efecto, en materia de violencia México merece que se hable de violencias y de efervescencia: son muchas en forma, son muchas también las maneras de contarla y de narrarla.

Todas esas narrativas coinciden, eso sí, en presentar la situación como un drama nacional y en los últimos años, es parte de nuestra hipótesis, en haber dotado a las categorías de desaparecido y de desaparición de un cierto poder de síntesis. Pareciera, sí, que la desaparición reúne el sentido de las múltiples violencias, en parte porque estas se le presumen a su ejecución y en otra parte significativa porque alrededor de la desaparición se ha ido gestando un verdadero campo (Bourdieu 1991).

Ese campo, en México, es peculiar, primero porque tiene esa textura especial de las cosas in statu nascens: se mueve, está haciéndose, es precario e inestable. Pero también porque la forma que está adoptando excede y precede al fenómeno en su manifestación mexicana. Precede, porque la categoría ha viajado y se ha transnacionalizado desde la experiencia de desaparición forzada en el Cono Sur latinoamericano y, a partir de allí, se ha consolidado en la legislación internacional, se han desarrollado alrededor de ella profesiones y organizaciones y, en ge- neral, se le ha ido dando forma a modos reconocibles de tratar el delito y de gestionar el dolor y el reclamo en las víctimas que la desaparición produce (Gatti 2008). Y excede, porque, aunque la desaparición preexiste, aunque no es propia de México, se está manifestando en este país de una manera tan colosal como particular. Las cifras abundan en magnitudes y en variaciones sobre esas magnitudes: grandes números, varias fuentes y gran indeterminación en las cuentas $^{3}$. Excede también porque las formas en las que se presentan las desapariciones actuales no son solo las que la figura de la desaparición forzada dice que han de ser; hay en el país otros modos, otros casos, muchos, que no se acomodan a aquel molde, no entran estrictamente en su definición.

Entre el precedente (de las desapariciones de otras coordenadas) y los excesos (de la desaparición mexicana) algo se agita enormemente en torno a esta figura: las formas, los dispositivos jurídicos, los aparatos de gestión y los imaginarios construidos alrededor de la desaparición están permitiendo visibilizar

337435 personas consigna el Registro Nacional de Datos de Personas Extraviadas o Desaparecidas (RNPED) del Gobierno de México en su última cifra de 2018 a partir de denuncias presentadas ante las autoridades ministeriales del fuero local y federal. Estas cifras están constantemente expuestas al cuestionamiento de diversas organizaciones civiles nacionales e internacionales y se presume que las personas desaparecidas en el país son bastante más de las que el registro consigna puesto que hay muchos casos que no son denunciados (Amnistía Internacional 2016: 11). Para mayor información y análisis de la metodología de registro del RNPED, véase Centro Diocesano para los Derechos Humanos Juan Fray de Larios (2017). Existen asimismo otros esfuerzos de organizaciones civiles e instituciones académicas por producir datos más fehacientes acerca de las desapariciones en el país. Sin embargo, estos son limitados y parciales. Es el caso, por ejemplo, del Observatorio sobre Desapariciones e Impunidad en México, que ha producido algún informe sobre la situación de las desapariciones en el Estado de Nuevo León. Como en los otros documentos, en el informe se destaca la dificultad de hacer un uso preciso de la categoría de desaparición, no siendo siempre claro si se trata de crímenes con o sin involucramiento estatal, lo cual revela, dice el documento, «la multidireccionalidad del fenómeno» (FLACSO 2017: 7). Por lo tanto, no pareciera que se trata de una intención de distorsión de las cifras por parte de las instancias oficiales, renuentes al reconocimiento del problema. No, o no solo, pues la indeterminación de las cuentas está dada por la dificultad de categorizar un fenómeno que, en la desmesura de su suceder actual, como intentamos demostrarlo a lo largo de este texto, enfrenta los problemas de dar con un nombre que lo comprenda cabalmente en su realidad sensible (Koselleck 2012). 
sus desviaciones, ponerlas en significación con las desapariciones del pasado, renovar los aparatos de gestión, ensayar nuevas fórmulas jurídicas que logren normar el delito, activar nuevas demandas y formular otras formas de búsqueda. En todos estos aspectos el panorama es, como decimos, agitado y muestra lo que en perspectiva sociológica vemos como un campo en gestación, significando acontecimientos del presente y del pasado, con actores en constitución, construyendo sus posiciones, observándose en sus disputas, produciendo y reproduciendo saberes, desafiando y haciéndose de poderes.

Así, entre el precedente y el exceso, están las cosas al momento de iniciar nuestro trabajo de campo y aproximarnos al país, en junio de $2017^{4}$. Entonces, y no desde mucho tiempo atrás, la categoría se acercaba con nosotros hacia allá y empezaba a ser omnipresente: habían transcurrido para esa fecha tres años de la desaparición de los 43 estudiantes de Ayotzinapa y ese acontecimiento, lejos de disiparse, se ha consolidado hoy como un movimiento articulador de diferentes demandas alrededor del tema. Ha logrado hacer puente entre las desapariciones de los años setenta y las actuales estableciendo una continuidad, pero también importantes discontinuidades que exhiben otras formas de desaparición; ha propiciado la internacionalización del fenómeno, principalmente a partir de la constitución y llegada a México del Grupo de Expertos Independientes (GIEI) para realizar investigaciones sobre el caso Ayotzinapa. Más o menos al mismo tiempo se ha ido gestando otro movimiento alrededor de «las otras desapariciones ${ }^{5}$ a partir de

4 Que fue cuando dimos inicio a una observación sistemática de algunos lugares estratégicos para entender la desaparición mexicana, en varios puntos del país, sobre todo Ciudad de México, Monterrey y Saltillo. Aunque este texto se apoya sobre todo en lo trabajado en esta primera aproximación, a esa entrada al campo se le fueron agregando posteriormente las que resultaron de otros viajes, siempre entre ambos autores: en noviembre de 2017 (Morelia, Guadalajara), en septiembre de 2018 (Palenque, Tenosique, Ciudad de México) y en noviembre de ese mismo año (Ciudad de México). Si en los diarios de campo originales se consignaron los nombres reales de nuestros/as interlocutores/as, los que figuran en este trabajo son en todos los casos ficticios.

5 La expresión alude a las numerosas y menos visibilizadas desapariciones que están detrás de la presencia hegemónica en la opinión pública nacional e internacional de los desaparecidos de Ayotzinapa. Se refiere, además, especialmente y en concreto, al colectivo Los Otros Desaparecidos de Iguala, una organización de familiares del estado de Guerrero que, apenas dos meses después de la desapari- la convergencia de las muchas organizaciones de familiares de desaparecidos y de apoyo a esos familiares en lo que se conoce como Movimiento por Nuestros Desaparecidos. En gran medida por la presión y el trabajo de esas organizaciones reunidas $-35-\mathrm{y}$ de la intervención del Alto Comisionado de las Naciones Unidas para Derechos Humanos que asesora jurídicamente sobre la materia, en el transcurso de nuestro trabajo en México el Congreso aprobó la Ley General en Materia de Desaparición Forzada de Personas, Desaparición Cometida por Particulares y del Sistema Nacional de Búsqueda de Personas. En paralelo, el goteo -casi chorro- de crímenes sufridos por migrantes que atraviesan México hacia el norte se encuentra con desaparición y desaparecidos cada vez con más frecuencia, y articula movimientos todavía hoy muy jóvenes, como la Caravana de Madres de Migrantes Desaparecidos o la I Cumbre Mundial de Madres de Migrantes Desaparecidos.

En fin, múltiples actores, saberes técnicos que se reproducen en diversas profesiones, normas jurídicas, protocolos de procedimientos, investigaciones académicas y narraciones periodísticas hacen de la desaparición en el México actual un caso de especial interés para la mirada atenta al tema y es sin duda así para el proyecto de investigación que hasta aquí nos trajo ${ }^{6}$. En efecto, este trabajo se inscribe en una investigación más amplia que procura entender cómo se ha ido transnacionalizando la categoría de desaparición, y cómo, desde su manifestación original,

ción de los 43 estudiantes, en noviembre de 2014, comenzaron a congregarse a partir de las investigaciones forenses sobre el caso Ayotzinapa replicando una modalidad de búsqueda y detección de fosas clandestinas en este Estado. El colectivo Los Otros Desaparecidos de Iguala ha dado posteriormente lugar a la organización de las Brigadas Nacionales de Búsqueda que despliegan su acción en otros estados del país; también a la creación, en el mismo municipio de Iguala, de la llamada Ciudad Víctima, un centro de atención integral para familiares de desaparecidos del estado de Guerrero.

6 Se trata de Desapariciones. Estudio en perspectiva transnacional de una categoría para gestionar, habitar y analizar la catástrofe social y la pérdida, financiado por la Dirección General de Investigación Científica y Técnica de MINECO (CSO2015-66318-P) para los años 2015 a 2019. Más detalles el proyecto y del programa de investigación que lo contiene, Mundo(s) de víctimas, pueden encontrarse en <http://victimas.identidadcolectiva.es/> (fecha de acceso: 10 abr. 2019). Es necesario agradecer la ayuda de Gabriella Citroni, sin cuyo conocimiento del campo mexicano de la desaparición y de su gente mucho de lo que hemos escrito no hubiese sido posible. 
aquella que termina consolidándose en la Convención, esta circula y, en ese andar, van haciendo su aparición otras formas más complejas, aún indeterminadas; en algunas de ellas ni el Estado ni agentes paraestatales son ya necesariamente los responsables directos del delito; en esas y en otras, ni son las mismas de entonces las víctimas que la desaparición produce. El trabajo desarrollado muestra que aquella categoría, que aún ordena el panorama de la desaparición a nivel planetario, ya no contiene todas las manifestaciones del fenómeno, especialmente en México. Aquí, la categoría se desborda: desapariciones sin Estado, desaparecidos en contextos no autocráticos, desaparecidos vivos...

El panorama se presenta caleidoscópico, tanto por su manifestación multiplicada en varios países y situaciones, como por su compleja configuración a nivel local. Enfocamos, en efecto, un objeto no solo multisituado, sino desbordado, activo, en movimiento, que trabaja bien con hipótesis que dicen que la categoría se transnacionaliza, que recorre mundo, y con otras que hablan de apropiaciones y modulaciones locales. En este texto buscamos anclar esos dos movimientos al tiempo que nos paseamos por el paisaje mexicano de la desaparición y lo haremos apostando por una etnografía a cuatro manos que recorre distintos escenarios. Ese trabajo tiene algunas particularidades: la menor es que la hacen dos sociólogos; otra, quizá relevante, es que ambos procedemos del Cono Sur latinoamericano, que uno vive en México, que otro no pero trabaja hace años sobre desapariciones; y la seguramente más importante es que lo que hicimos replica un modo de investigar que se ha apeado antes en otros parajes en donde la categoría también lo ha hecho (Sao Paulo, Melilla, Buenos Aires, Santo Domingo, Vigo o Madrid, en cada uno con diferentes casos y tipos de desaparición) aunque adaptándose ahora a un contexto, el mexicano, en el que la desaparición es cosa dispersa, que se está gestando, en donde viene de lejos y de antes pero donde también está dentro y se reorganiza y se redefine. Hemos querido seguir el dictado de uno de los trabajos precursores de la etnografía multisituada, dejándonos guiar por uno de sus principios, follow the thing (Marcus 1995), sabiendo que la cosa es cosa en movimiento, de esas difíciles de decir para lo que por oficio ambos somos.

De todo eso, sale esto. No es una monografía del lugar. Tampoco lo pretende. Es una aproximación en el doble sentido que esta palabra contiene: se acerca todo lo posible al fenómeno que estudia, pero no llega hasta el final; como decimos, el campo está en constitución y tanto que, aunque sigamos a la cosa, la cosa se sigue moviendo. Desde este acercamiento, el resultado se presenta como una etnografía en paralelo redactada por dos integrantes de un mismo equipo construyendo y observando un mismo campo de investigación, construyendo sus diarios y sus notas como el manual exige -individualmente-, pero de manera dialogada y por ello cruzada ${ }^{7}$.

El texto está organizado por lo que entendemos son los grandes rasgos del campo mexicano de la desaparición: que deriva de un precedente de una «desaparición originaria» (Gatti 2017) que se ve excedida. EI primer apartado rastrea el origen, da cuenta de los principales hitos en la gestación del campo, explora en el desembarco de la categoría en el país, en quienes con ella migran y en las conexiones con las experiencias de otras geografías. Partiendo de allí, el siguiente esboza los problemas de una categoría desbordada para dar cuenta de las situaciones de desaparición que enfrenta el país. Frente a ello, las notas de campo del apartado muestran los esfuerzos y la necesidad de producir nuevas conceptualizaciones alrededor de la desaparición. A continuación, la representación del fenómeno a partir del sobrecogimiento: mapas, conteos, narrativas que intentan aprehender lo que en principio resulta inasible de la desaparición. También hacia ello se dirige el apartado siguiente, que aborda una práctica inescindible y hasta constitutiva de la desaparición, la búsqueda, sus modos, sus agentes, sus métodos. Acercándonos al final, todo vuelve a la intuición de partida, la desmesura: la desaparición llega hoy a significar a sujetos fuera de la ciudadanía y de cualquier protección; no porque hayan sido expulsados, quizá porque nunca han estado allí.

\section{LAS VÍCTIMAS Y LA CONEXIÓN ARGENTINA}

En México, aunque ya parece que se lleva desde siempre hablando de ello, la desaparición llegó hace

7 Etnografía multisituada en paralelo nombra el tipo de trabajo que se desarrolla en el proyecto Desapariciones: un objeto transnacionalizado al que se interroga del mismo modo en sus distintas localizaciones para resolver un mismo problema teórico. Aunque la etnografía está pegada aún a una cierta mística de la autoría, esta lo es en equipo: el texto es entonces propio, de autor, y no lo es, es colectivo, pero sale de plumas diferentes. Esas tensiones no se resuelven aquí ni siquiera se abordan, solo se practican sin someterlas ni a censura ni a borradura, tan solo a discusión antes de fusionarlas en un texto compartido. 
poco pues pocos han sido los hechos que han sido nombrados como desaparición. No es raro: los aterrizajes en contextos locales de las categorías presuntamente universales que componen el complejo paquete de los derechos humanos suelen ser silenciosos, pero cuando están, parece que están allí desde siempre. Es el caso. Si se rastrea la genealogía de esos aterrizajes, interviene de todo: agentes nacionales e internacionales, categorías del derecho internacional y tradiciones locales, experticias del mundo humanitario y oficios propios de las viejas construcciones de derecho, las de la ciudadanía. Cosas bien concretas, mucho más que las cuestiones a las que afectan estos derechos, de definición difícil -la vida, la existencia, la muerte, lo duelable-. Tan concretas como los hitos, siempre locales y específicos, que intervienen en los procesos de vernacularización (Cowan 2010) de los derechos humanos. En lo que hace a México y a la categoría de desaparecido, dos de esos hitos parecen destacar en la constitución progresiva de un campo de los derechos humanos y del desaparecido.

Uno es el nacimiento de la víctima como actor político. Durante nuestra investigación contactamos en Ciudad de México con una activista que cubre un abanico amplio de las situaciones que el campo contiene: familiares de desaparecidos originarios, familiares de "los 43», familiares de "los otros desaparecidos», los que no son de Ayotzinapa. Sitúa el nacimiento de ese campo que habita en la acción encabezada por Javier Sicilia, el Movimiento por la Paz con Justicia y Dignidad de 2011, y en su capacidad de nombrar a una población como "víctimas». Las marchas por todo el país de ese movimiento colocaron en escena a un actor colectivo hasta entonces disperso, la víctima, un contenedor de subjetividades planetario (Gatti 2017), formidable, unificador. Las venas de las víctimas de la violencia comenzaron de entonces a esta parte a ordenar el sistema circulatorio de la vida política mexicana y a constituir lo que derivará, no mucho después, en una cuestión general. Hasta entonces, lo que pasaba era ininteligible; la marcha iluminó, provocó salidas del armario, de gente y de conceptos: «Estábamos viviendo una guerra y no sabíamos cómo se llamaba (...). No lo sabíamos nombrar», nos dice esta entrevistada. Instalada, la categoría de víctima se mueve con vida propia y arrastra consigo agentes, técnicas, procedimientos, representaciones globales, muy eficaces: antropólogos forenses, comisiones y comisionados de la verdad, tribunales de los pueblos, agencias de derechos humanos, académicos expertos en categorías de gestión o de análisis, genetistas... México se ha llenado de ellos; el mundo disperso de las violencias se empieza a hacer inteligible.

Entre esos desembarcos, uno especialmente significativo y que en estos años ha demostrado ser exitoso es el de la categoría desaparecido. Viene, por supuesto, en la valija del poderoso aparato de representación y gestión de la realidad del humanitarismo (Fassin 2010), muy presente en la vida pública local reciente. Viene también de mucho antes, de casos que se desplegaron por la geografía latinoamericana desde los años setenta del siglo XX en adelante. En efecto, también la experiencia histórica mexicana tiene un capítulo de desapariciones de las de antes $y$, aunque quizás no muy conocido internacionalmente, sí hubo un activo y siempre presente movimiento de denuncia y solidaridad con los afectados (González Villarreal 2012). Pero la categoría tiene también unos portadores más concretos, de presencia constante en no importa qué foro, seminario, charla o comisión que en México se proponga sobre el asunto. Los vimos en Morelia, en un congreso de literatura en 2017; en Monterrey, el mismo año; entre antropólogos, en Ciudad de México en 2018; en otro diverso en orientaciones profesionales que se celebró en la capital también ese año: siempre hay argentinos y argentinas.

En el primero, por ejemplo, un congreso de humanidades y derechos humanos del que uno de nosotros tomó parte, México era el tema, pero estaba repleto de personas argentinas. En este caso estaban allí desde tiempo atrás, llegadas a México en los años de la dictadura militar de los setenta; se les llama argenmex y en la academia mexicana son legión. Ocupan un lugar de referencia entre los agentes que se disputan un buen espacio en este campo en gestación. Son viejos peronistas, montoneros veteranos, intelectuales comprometidos, poetas. Representan los primeros pasos de la historia de la categoría desaparecido, de la que son portavoces y también férreos vigilantes. Velan por su preservación, la de la buena categoría y la de la manera adecuada de administrarla socialmente. La cuidan y no descuidan decir que son sus dueños, al menos de su origen. Se comportan como tales: relatan luchas, desafíos, fracasos y logros. Animan y abrazan. Clasifican y dan ejemplo. Certifican.

Llamémosle a aquel desaparecido que estas colegas preservan «desaparecido originario» (Gatti 2017). Es aquel que inspira lo que formalmente la Convención tipifica como «desaparición forzada», donde el victi- 
mario es el Estado, la víctima un ciudadano, y el contexto es el Estado de derecho suspendido, y que se inspira en lo que ocurrió en la Argentina en los setenta, cuando en el marco de un régimen autocrático el Estado sumergió a parte de su ciudadanía en las catacumbas de la excepción. Sistemático, calculado, maquinal. El dispositivo desaparecedor (Calveiro 2006) tuvo allí éxito, y lo tuvo también una respuesta social que consiguió aupar este término al estatuto de categoría del derecho humanitario internacional y a sus activistas más renombrados (Madres de Plaza de Mayo, Abuelas...) al de ejemplos ${ }^{8}$.

Hoy la categoría viaja, y no para, y aún al precio de homogeneizar bajo un mismo nombre situaciones dispersas (Anstett 2017), estas ganan nombre, aunque lo que allí pase no corresponda a lo que la categoría designa. Laura es periodista. Nos interesaba hablar con ella porque el drama social es aquí actual y es allí donde se desarrolla ese oficio; porque el periodista tiene la particularidad de posarse levemente sobre la realidad y ello le permite ofrecer una representación amplia de esta; porque el acceso de este oficio a los hechos que nosotros llamamos sociales es inmediato, y en cambio el nuestro tardío; porque esa representación de la realidad es por tanto fresca, o caliente, mientras que en sociología la hacemos pasar por la cocina, o por el congelador. Laura además es argentina e hija de desaparecidos. Un vehículo que transporta referentes pues. Integró la Asociación H.I.J.O.S. de allá y fue también fundadora de H.I.J.O.S. de acá, en México. Hace no mucho publicó un libro

8 Que el caso argentino sea el ejemplar no significa ni que fuese el único ni que fuese el primero, pero sí que se constituyó en el modelo con referencia al que la Convención de 2006 dio forma a un concepto general de desaparición forzada. Antes o al mismo tiempo o poco después que el estado argentino desapareciese ciudadanos durante la dictadura 1976-1983 ocurrieron fenómenos no muy distintos en Uruguay, Colombia, Chile, Brasil o Guatemala o, hasta en Argelia, si se quiere ampliar esta consideración. Incluso también en el México de los años 70 (González Villarreal 2012). Si a Argentina puede atribuírsele la propiedad del original es porque convergieron allí capacidades (de movilización, de difusión, de denuncia) que dieron lugar a un fenómeno realmente único, propio de lo que ahora llamaríamos innovación social: se inventó nada menos que un nombre para un horror impensable, y se le dotó de contenido propio, tanto que se constituyó en modelo. No había nombre, ni referentes, ni ejemplos. Un trabajo de creatividad social, de producción de conocimiento colectivo, que es por lo demás, el que se está desarrollando ahora en México ampliando los horizontes de la categoría y el tipo de casos y cosas que abarca. sobre los 43 de Ayotzinapa. Sus dos experiencias le facilitan la circulación de referencias: desapariciones viejas y nuevas, reacciones de allá y de acá. Ayotzinapa, guerrilla, revolución llenan los primeros minutos de nuestra conversación. Desconcierto los segundos, cuando se habla de migrantes desaparecidos, de desaparecidos que se parecen poco a los desaparecidos, aunque se les llame así. En lo que concierne a los primeros -los de los setenta, también los 43 de Ayotzinapa- puede entender, nombrar, colocar México gracias a Argentina: tienen un aire de familia, sí, pues el original argentino, ese del que procedemos, es producto de la razón de Estado. En los segundos no: hay pobres, miseria, desechos. Nada huele ni a ciudadanía ni a política en el sentido viejo de política. Qué distinto a aquello, constata. Tanto que cuando va a Argentina no la entienden, porque «no es lo mismo, no, no es lo mismo».

Ayotzinapa es en algo, al menos en algo, familiar: hay movilización, el Estado está, más o menos está. Pero en estas otras -migrantes descuartizados, mujeres violadas y olvidadas, cuerpos licuados- no hay ciudadanía, no hay, como allá, un único sujeto, no hay, como allá, patrón desaparecedor. Desaparecido se queda corto; no alcanza a nombrar lo que pasa en México. México desborda lo que la ya vieja categoría de desaparecido no contiene. El desconcierto con ese presente que escapa de su origen alcanza a Laura y a nosotros, portadores de un mismo patrón comparativo. «Comparación no es razón» (Anstett 2017). La desaparición tuvo ese origen, pero ahora en México lo excede.

\section{«LA MALDITA PALABRA FORZADA»}

Tucídides, padre fundador de nuestra historiografía política y antropológica, planteó ya en su modelo básico de relato la alternativa de una historia condicionada por factores lingüísticos o extralingüísticos. Todo lo que ocurrió en la guerra civil, asesinatos, horrores, enfermedades, esclavitud, y todo lo que les sucede a los seres humanos, se recoge en sus capítulos narrativos, mientras que, por otra parte, todo aquello que la gente pensaba y estructuraba mentalmente sus experiencias de sufrimiento y sus esperanzas constantemente renovadas, hay que buscarlo en los diálogos y en los discursos que recoge en otras partes de su obra (Koselleck 2004).

No es que no haya nombre, es que el que existe explica solo una parte de la cosa. Mejor dicho, vale 
solo una parte del nombre que existe. Desaparición forzada es a cabalidad el caso de muchos casos en México, pero no de todos. Desaparición, en cambio, sirve para todos. Significa bien ese estado del ser que roza lo fantasmal, lo absurdo, la falta de estado y de existencia, la liminalidad, un estado entre la vida y la muerte (Gatti 2008; Schindel 2012; Mahlke 2017). También lo que todo ello deja como consecuencia: los sufrimientos que exceden lo humanamente soportable que hay en los delitos que se definen como de lesa humanidad (Rousseaux 2017). Quizá por eso, desaparición sea una palabra que en México sirva para dar cuenta de las muchas violencias, de los horrores desmedidos, del sin sentido. Para significar todo eso sirve desaparición, pero no para todo sirve el adjetivo que la acompaña y la acota en la definición institucionalizada: forzada. Eso que termina consolidándose en el artículo 2 de la Convención es la obra de agentes del Estado o de otros con autorización o aquiescencia de este. Es una fórmula que traduce bien las experiencias del pasado, es decir, aquellas desapariciones que convenimos en llamar originarias, cometidas paradigmáticamente por gobiernos dictatoriales sobre individuos ciudadanos que aquellos regímenes suponían enemigos del Estado, militantes con una clara identidad política.

Eso no alcanza a todos los casos de desaparición en México. Encuadra el de muchos, y esos muchos la defienden. Claro está, entran en un orden de reconocimiento ya establecido, pautado $y$, al menos en el plano internacional, normado, plausible. No es el caso de otros tantos, que de todo ello se ven excluidos, pero a la vez convocados porque, al menos, significa algún tipo de reconocimiento. Entre las forzadas y las que no lo son se estructura en gran medida el campo de la desaparición en México. Está allí en juego una medición lingüística entre lo que la experiencia va dando de sí, que es algo más que lo que dispone la desaparición forzada, y la posibilidad de comunicar aquellos datos sensibles (Koselleck 2012). Es una distinción que genera controversias: colectivos que representan las viejas desapariciones niegan a veces a los de otras más recientes la legitimidad para usar el término y estos a su vez sondean la manera de hacer de la categoría algo propio. Así ocurrió en una reunión que se celebró en septiembre de 2018 en Ciudad de México: miembros de los grupos de desapariciones de alcurnia, las originarias, rebajaban a "secuestro» lo ocurrido a los desaparecidos sin marca política, mientras que en la reunión no había referencia alguna a la desaparición de migrantes que apenas un mes después constituyó el motivo de la I Cumbre Mundial de Madres de Migrantes Desaparecidos. Como sea, el debate sobre las desapariciones en México recorta los tiempos remitiendo algunos casos al referente del pasado y condicionando a otros a definiciones más precisas a futuro, pero que envuelve a todos en un denso y complejo presente en el que está en juego una acepción mexicana de la desaparición, sobre todo en los días que corren durante nuestra primera entrada al campo, que está siendo discutida en el país a propósito de una próxima ley sobre el tema.

Adrián es coordinador del departamento de asuntos jurídicos del Alto Comisionado de las Naciones Unidas para los Derechos Humanos en México. Tuvimos con él una larga entrevista. De múltiples maneras nos dice que en el contexto mexicano la categoría de desaparición forzada está superada; que esta se origina en contextos de represión política pero que "aquí va más allá»; que difiere porque, aunque esas desapariciones forzadas en México persisten, hay otras, muchas, que las cometen agentes no estatales que privan de la libertad a las personas con el objeto de desaparecerlas. Destaca la complejidad del fenómeno de la desaparición, el peso del origen de la categoría para abordar la complejidad y la preocupación de los juristas por hacerse con conceptos que sean capaces de captar la intricada trama de los «medios comisivos del delito» que hacen esa complejidad. La represión política no es suficiente en el caso mexicano y el tipo jurídico de la desaparición forzada de personas se queda corto y deja muchas zonas de realidad en penumbra. Transformarlo es necesario para recoger el "caleidoscopio de situaciones», dice, para «no encerrarse en cada cristal» y debatir correctamente la opción de ampliar la categoría o de apuntar a acepciones específicamente mexicanas. «El concepto de 2006 es castrante», añade. Nos propone un «concepto jurídico ampliado» con respecto al de la Convención. No de otro modo podría servir en México. Cita, marca, señala, toquetea con pasión (jurídica) un libro que sostiene su argumento (Naciones Unidas-Comisión Nacional de Derechos Humanos 2015): «Ahí adoptamos un concepto amplio que creo que es el que responde mucho mejor a la situación mexicana, entendiendo por esto toda persona cuyo paradero sea desconocido». Deja fuera, pues, «el maldito adjetivo", forzada, y así la ampliación se arrima al desborde, que es su dato mexicano: «con esa definición -nos dice-, es que todo esto se ha empezado a mover, porque las categorías tradicionales no 
son útiles para responder a las realidades como las que México está enfrentado».

¿Qué es entonces desaparecer en México? El actor comisivo puede ser o no el Estado; la acción desaparecedora a veces es tal, pero a veces es omisión, desprotección. Así que, en México, la desaparición no es necesariamente por acción, es también por descuido, por una suerte de desprotección radical mediante la cual mucha gente queda fuera de la ciudadanía, abandonada. El marco legal que instituye el delito de la desaparición forzada -aquel ya mencionado de la Convención- se inscribe en una concepción del sujeto que es tal por el reconocimiento que la ley le otorga. No parece ser ese el caso de muchas de las desapariciones en México. En cambio, lo que en estas se ve, es lo que el Estado no ve, individuos que quedan fuera de su instrumental de visibilización, del derecho. Expulsados de la ley, quizá nunca reconocidos allí, ajenos a la "ficción originaria de la soberanía nacional» y al derecho, expresiones de la ruptura entre lo humano y la ciudadanía (Arendt 2004; Butler y Spivak 2009), anomalía fundamental, por tanto, es todo lo que hay en esas otras desapariciones que no son forzadas.

Daniela, que también es jurista, abogada de brega, directora actualmente de un organismo dedicado a proveer de cobertura y protección a los migrantes que atraviesan México, dice que allí el Estado es bifronte: de un lado, protege y cuida; del otro, olvida y excluye: "Tiene una institucionalidad ejemplar y otra insensible». Por la primera, se entiende el poder armonizador que derivó en las viejas desapariciones. Por la segunda, se explica la incapacidad profunda de manejar un «registro de lo sensible» (Rancière 2009) que permita ver, escuchar, palpar otras cosas que no sean las cosas que sabe registrar. En una el Estado es lo que hace, que es tanto el bello sueño de la ciudadanía inclusiva como sus desmanes. En la otra el Estado es lo que no hace: la falta de cuidado, de atención, de registro. No cuenta: ni narra, ni contabiliza, ni le importa. La desaparición en México es, sí, «forzada de personas» si por eso se entiende un trabajo de exterminio planificado que tiene una traducción en un hecho puntual, brutal. Pero es sobre todo una rutina que hace a una forma de gestionar la vida. 0 de no hacerlo con relación a parte de su población. La "acepción mexicana» de la desaparición es eso, dice Daniela, la vida desaparecida de la idea de vida.

Pero el derecho es uno de los sistemas de medida de la realidad; demanda contener; necesita concep- tos, categorías, tipos. En la ley mexicana en materia de desaparición se plasmará una adjetivación alternativa a la de forzada, pero definida con sus mismos elementos, fijándose en el ejecutor, en el Estado, en sus agentes y en quienes sobre él orbitan. Serán en la ley desapariciones "cometidas por particulares». Poca cosa define ese nombre. Define más bien el límite, indica la línea de lo que hay fuera del Estado. Más allá de ese límite, el panorama es inconmensurable, irrepresentable, de múltiples violencias, descontrolado, imposible de ser significado y ordenado con una palabra que defina, que acote, que simplifique. Si acaso, el significado puede ser intuido en esos particulares que no son Estado: cárteles, grupos criminales, crimen organizado, que quizá sea la expresión más consolidada en el lenguaje cotidiano, en el del periodismo y el de los políticos. La cosa es que particular señala 'lo otro del Estado', pero ¿cómo no pensar el Estado desde ese otro lado? Enseguida aparece la palabra sobre la que uno de nosotros, el menos asiduo al lugar, pondrá escucha de extranjero: colusión. Es una palabra muy dicha en México. Se dice tanto como crimen organizado. Colusión y crimen organizado son palabras que hacen presumir. Y lo que se presume es una complejidad entretejida de múltiples poderes, siempre de hecho, casi nunca de derecho, que dificulta el esclarecimiento sobre el acto y el actor comisivo. También se presumen las múltiples violencias que esconde y a la vez visibiliza el fenómeno de la desaparición en el país. Hasta esa ley que hacia mediados de 2017 se está debatiendo en el Congreso le pone nombres a los horrores cuando dispone la pena para quien "oculte, deseche, incinere, sepulte, inhume, desintegre o destruya, total o parcialmente restos de un ser humano o el cadáver de una persona, con el fin de ocultar la comisión de un delito... ${ }^{9}$.

\section{RACIONALIZAR LA DESMESURA}

Tras la guerra de Vietnam, tras los años del senderismo en Perú, así como en Colombia con los paramilitares y en Ruanda después del genocidio, emergieron voces que explicaron qué había sucedido ahí. Cuando le llegue ese momento a la frontera, se oirán voces parecidas. Se irán remembrando los hechos y se conocerá qué hubo detrás de masacres

9 Artículo 37, 159 de la Gaceta Parlamentaria, n. 48884-IV, 12 de octubre de 2017. 
como la de 72 migrantes, en San Fernando, el 23 de agosto de 2010; así como el hallazgo de decenas de hombres y mujeres enterrados en fosas clandestinas de Tamaulipas, Coahuila y Nuevo León.

¿Y mientras tanto...? Mientras eso pasa, tal vez el silencio de esta frontera se expresa con un lenguaje críptico, a través de contraseñas que no se pueden comprender. $\mathrm{O}$ tal vez también, como dice el escritor Juan Villoro, no exista sistema lingüístico alguno capaz de dar cabida a tantos horrores con los que acabó la primera década del siglo XXI mexicano (Osorno 2017).

El sinsentido puede gestionarse con muchas estrategias, se pueden desarrollar para eso muchas narrativas. En Argentina, ante la desaparición originaria, las narrativas hegemónicas eran y son conservadoras: como el desaparecido, se dijo, voló los soportes de nuestra identidad, lo que conviene, y se hizo, es recomponerlos, y se recompusieron en base a la genética, el trabajo de archivo, la monumentalización de la memoria (Gatti 2008). Luego surgieron otras estrategias, más paródicas, más abiertas, pero las primeras dominaron y explican el despliegue ético, estético, político y hasta antropológico de Madres de Plaza de Mayo, Abuelas de Plaza de Mayo o HIJOS.

En México ese trabajo de dar sentido al sinsentido está todavía en gerundio, pues está pasando, y ante el exceso y el desborde las estrategias que se están poniendo en marcha muestran ciertas singularidades. Se sostienen por tres verbos: cartografiar, nombrar, buscar. Los dos primeros conjugan casi todos los trabajos modernos de racionalización (Anderson 1992; Foucault 1997). El tercero, en cambio, es más propio del campo de la desaparición, en especial de la mexicana.

\section{CARTOGRAFIAR Y NOMBRAR EL HORROR}

$X$ es fotógrafa y trabaja en un colectivo de periodistas críticos en Ciudad de México. Camufla su nombre en el del colectivo, pues como muchos periodistas, se la juega. Aquí será $\mathrm{X}$. $\mathrm{X}$ traza mapas de cosas complicadas: migrantes desaparecidos, familiares víctimas, el poder. En 2006 hacía notas rojas, cubría sucesos: fotos de descabezados, de ejecuciones, de mujeres violadas, de mutilaciones sexuales, de reventadas, de destrozadas, de secuestros. El necroteatro (Diéguez 2016) de la guerra del narco y contra él. Todo eso quedaba sepultado en un archivo policial u olvidado en una hemeroteca: no había, cuenta, cómo archivar aquello en orden. Hasta que empezó a notar que su trabajo era funcional a ese «folklore alrededor del cuerpo", y que había que buscar un modo de juntar esos fenómenos dispersos. Las notas rojas baldías, sin categorías, debían encontrar un eje.

Y empezó a cartografiar: armó primero un proyecto que en un mapa de México reúne puntitos dispersos; cada uno remite a casos de nombres distintos, pero al verlos juntos se los percibe como una parte de una trama, y el mapa mismo, que ahora existe y antes no, lo manifiesta: feminicidios, desaparecidos, mutilados... comparecen, por el mapa, como siendo parte de la misma violencia. Siguió tiempo después con un proyecto sobre la masacre de 72 migrantes en San Fernando, en el norte, en 2010; técnica y gráficamente es impactante y al palimpsesto del mapa de las violencias mexicanas le agrega un viejo invisible de la cuestión social: el migrante. Ya en 2017 le dio cuerpo a la búsqueda, en un proyecto largamente premiado que acude a términos del poderoso diccionario del humanitarismo, a sus dos más poderosos términos: víctima y desaparecido... Y así sigue.

No es la única: hemos encontrado en distintos lugares de México a ingenieros padres de desaparecidos que cruzan mapas de carreteras, con otros de desapariciones, con otros de movimientos policiales y deducen de esa superposición cosas como ubicaciones de casas de seguridad del narco. O a informáticos con conciencia social que inventan algoritmos y aplicaciones para poder ubicar fosas comunes y prever desapariciones. Es un ejercicio no muy distinto del que hacen los que trabajan en «arqueología forense», que repiensan mapas disponibles "para conectarlos de nuevo con la realidad que los hizo posibles» (Weizman 2018: 20). O lo que hace el cartógrafo de la obra homónima de Juan Mayorga (2017: 14): «El mapa hace que (...) desaparezcan las diferencias (...). El mapa hace visibles unas cosas y oculta otras. Los mapas cubren y descubren, dan forma y deforman». Crean. Lo mismo hizo X: reunió en un plano homogéneo fenómenos dispersos. No les da nombre porque tienen muchos, pero propone ejes de comparación. La nota roja mostraba los sucesos dispersos, el mapa propone tramas. El nombre de esa trama, en México, es desaparición.

Así parece, el mapa de la violencia se está haciendo en torno al concepto de desaparecido. En el norte de México, en el estado de Coahuila, está Saltillo, una ciudad muy golpeada, en un pasado que a esta fecha no tiene mucho más de un lustro, por formas 
varias de terror: terror de Estado, terror del narco, uno y otro hacia gente de allí -mexicanos- o hacia gente de más allá -migrantes que pasan por la ciudad hacia los no muy lejanos Estados Unidos-. Ahí trabaja Clara. Clara se dedica a reunir víctimas, fenómenos, cuentas... y a hacer las cosas pensables. Una de las iniciativas que fomenta es un "registro ciudadano» de los desaparecidos en todo México. "Ahorita cada uno tiene su mapa», nos dice, y eso conduce al subregistro de las violencias y de los que las sufren que o no se cuentan o se cuentan en listas separadas, que no funcionan así nunca como «población». Unos suman no localizados, otros ausentes, otros desaparecidos originarios, otros desaparecidos puntuales, otros extraviados. Y el horror dispersado no tiene valor político, dice Clara. Dentro de ese proyecto, sobran controversias: muchos abogan por dar cuenta solo de los desaparecidos de raíz política; otros defienden incluir también las desapariciones producto de la acción de particulares; algunos pelean por contar a los migrantes no mexicanos que son desaparecidos en tierras mexicanas, aunque otros no... A Clara no le importa, porque el registro que auspicia no aspira sino a contar, literalmente a eso: a dar cuenta, a dar cuento (Edkins 2011).

El registro es, pues, un mapa que se articula sobre un nombre, desaparecido, que aparece como el metafenómeno, la clave de bóveda, el eje, el patrón. Feminicidio, profesionistas haciendo trabajos forzados, mujeres en situación de trata, formas diversas de trabajo esclavo, migrantes esfumados en el camino, cuerpos decapitados, cuerpos secos en el desierto, cuerpos sin órganos, migrantes secuestrados, vivos y muertos, secuestrados por la acción represiva del Estado o de la violencia de agentes privados. México desborda violencia. La categoría desaparecido, porque la cuenta, contiene la desmesura.

\section{BUSCAR PARA CONTENER EL DESBORDE}

Buscar es la acción fundamental del campo de las desapariciones en México. En ello están todos sus agentes. Tanto lo es que podría decirse que la búsqueda es la acción que hace al desaparecido; que si no se lo busca no puede este ser. No era este el caso de las desapariciones que llamamos originarias, cuando quien desaparecía era un individuo ciudadano, inscrito en un marco de reconocimiento del que la desaparición lo sustraía, pero del que se sabía de su existencia. En México no. Aquí, la búsqueda es la condición de posibilidad del desaparecido. Tanto es la búsqueda al campo y tanto a la condición de desaparecido que podría incluso decirse más: el desaparecido produce agencia en quienes lo buscan (Irazuzta 2017); esta se traduce en múltiples formas y estrategias ejercidas por también múltiples actores que, con esa acción, intentan recomponer el sentido de la ausencia y de todo lo que se le presume a la producción de esa ausencia. Buscar es una forma de contener el desborde y de dar existencia a aquello que le da nombre: la desaparición.

Buscan fundamentalmente los familiares, pero también lo hace un amplio espectro de profesionales: antropólogos forenses, arqueólogos, genetistas, abogados, psicólogos, sociólogos... La lista es larga porque en México las formas de desaparecer son variadas, las personas a las que buscar muchas y diferentes y los lugares donde hacerlo amplios y diversos. Mucho más que lo que lo han sido para el desaparecido originario, cuyas búsquedas, aunque exigieron entonces un gran trabajo de sistematización de datos y de construcción de información para la localización de los sitios de enterramientos clandestinos, en correspondencia con un aparato desaparecedor centralizado, eran acotadas a espacios confinados y a poblaciones puntuales de individuos identificables.

Aquí y ahora, el espacio de búsqueda es tan amplio como el territorio y las formas en las que se busca son variadas. Hay una forma de búsqueda extendida y por ello conocida en el país y más allá del país, producida por una técnica específica y muy desarrollada en relación al mundo de la desaparición. Es la que en los estudios del ramo queda comprendida en el llamado "giro forense» (Ferrándiz y Robben 2015; Huffschmid 2015; Anstett 2017), que se desarrolla principalmente en el Cono Sur en las identificaciones del desaparecido originario y que, desde entonces y desde allí, viaja hasta donde la figura de la desaparición se haga presente. También a México y especialmente a cuenta del caso de los 43 de Ayotzinapa. Ayotzinapa ha instituido en el país la figura del antropólogo forense, también la noción de fosa, también la imagen del hueso y del vestigio como signo de desaparición. Ha instituido una forma de búsqueda que ha desbordado primero en los hallazgos de otros restos mientras buscaban a aquellos estudiantes, constituyendo a un grupo de buscadores alrededor de «los otros desaparecidos de Iguala». Ha producido un tipo de "familiar forense», instruido en esas técnicas, como a uno de nosotros nos ha tocado 
ver al presenciar un taller de búsqueda impartido por especialistas para organizaciones de familiares de desaparecidos, en Monterrey. Allí se les instruye en técnicas de expertos y con ese saber salen a campo, rastrean, marcan el terreno, encuentran... X, la periodista, ha retratado muy bien estas figuras y situaciones de búsqueda en uno de sus trabajos. Allí, se ve cómo quienes buscan hacen lo que el Estado no hace: buscan cuerpos, buscan vida, buscan justicia ${ }^{10}$.

También Daniela, aquella jurista de la que ya hablamos, hace lo que el Estado no hace siguiendo una fórmula de búsqueda que corresponde más a su oficio. Para Daniela buscar es esclarecer, seguir indicios, investigar, racionalizar, al fin, de esa manera en la que lo hacen los abogados y los investigadores de las novelas policíacas (Boltanski 2016). A esa fórmula le pone un nombre: «documentar el contexto». Como no hay en México una teoría de la acción desaparecedora hay que elaborar, creativa y minuciosamente, las circunstancias del delito, sacar de allí patrones, ver qué grupos operan sobre el territorio, cuál es su modus operandi y, en general, armar el rompecabezas que rodea el delito. Con ese método pueden llevar grandes casos a la justicia, como ocurrió cuando la Corte Penal Internacional sentencia a México por los feminicidios, o como pretenden que ocurra en los casos que su fundación atiende.

Daniela trabaja con migrantes, migrantes que atraviesan México en su ruta hacia Estados Unidos. Esos casos, dice, son el blanco perfecto para cometer una desaparición: no hay familia que los reclame, nadie los busca, no «existe en el resto de la sociedad el potencial de preguntarse por su paradero" ${ }^{11}$. No importan. Tan es así esa circunstancia que pareciera haber desapariciones en vida, como si quien desaparece hubiese estado desaparecido antes de desaparecer, como si para ser fuese condición haber sido encontrado desaparecido, como si la desaparición fuese aparición. Buscar en vida es otra invención mexicana en donde buscar es dar existencia civil, es registrar, dar ciudadanía a individuos que nunca se hallaron en ese orden de reconocimiento y que por eso son hasta fáciles de abducir. Buscar, en México, es importante, singular y capital porque, contrariando

10 Para quien quiera profundizar en la figura de la buscadora, es muy recomendable el trabajo de Periodistas de a Pie (2017) en "Buscadores».

11 Juan Yankelevich. 2017. ¿Puede Robinson desaparecer a Viernes? Policopiado: 2. a un Estado que hace que haya individuos que no cuenten, es la manera de revelar, de hacer visible, de comunicar que hay vidas que importan.

\section{EL DESAPARECIDO VIVO, A LA MEDIDA DE LA DESMESURA MEXICANA}

Hay en México un amplio espectro de desaparecidos vivos. Viven en un terreno sumergido en una niebla vieja, que no se mueve hace mucho tiempo. Es poderosa: ha sacado del registro de lo sensible a parte importante de quienes están en México, a los que ni cupo ni cabe ahora llamarles ciudadanos. Aunque se quiera: hacerlo sería justo quizás, pero también un grave error de concepto. Apenas si son sujetos, pues nunca habían llegado a formar parte del "campo de aparición» de lo que hace a un ciudadano, a un sujeto, a un existente (Butler 2017). Aunque se les llamase expropiados, marginales, pobres $u$ olvidados, nunca contaron ni se les contó. Tiene algo de inmenso escribir esto -desaparecido vivo-, pero da la medida de esta desmesura.

De lo que hablamos es de una importante proporción de la población de la que no se tiene registro ni nunca se lo ha tenido. Individuos de inexistencia civil: no hay constancia de su nacimiento ni por tanto de su defunción. Son un tipo más de esos que Ngai (2005: 5), pensando en los migrantes indocumentados, ha llamado "sujetos imposibles», puesto que son a la vez "una realidad social y una imposibilidad legal». Sobre esos sujetos en su conjunto solo cabe la suposición, la estimación, el cálculo aproximado. Probablemente operen sobre ellos técnicas de gubernamentalidad como los censos, probablemente sean considerados a partir de allí parte de la población, incluso una población (Chatterjee 2008), pero no hay rúbrica jurídica subjetiva de esa operación de conjunto. Son individuos perdidos entre la población, pero no son sujetos, no son ciudadanos.

¿Puede hablarse de desaparición en estos casos? No si tenemos en mente la posibilidad legal de la desaparición forzada, pero sí si atendemos a su realidad social. Hay sustracción del individuo de la protección de la ley; hay ausencia en tanto no hay posibilidad de aparición en el orden civil; hay esa indefinición entre vida y muerte en ese mismo orden; hay, sobre todo, invisibilidad. Y aunque hay cosas de la vieja desaparición que no hay -no hay la acción represiva del Estado o su desidia ante la comisión del 
delito de desaparición cometida por particulares- sí hay, en cambio, algo que también le daba su consistencia especial a aquella: desprotección, descuido y abandono en la producción de ciudadanía. La situación es, incluso, de inexistencia de las condiciones de posibilidad como para que se produzca una desaparición, puesto que se trata de individuos que nunca han estado aparecidos; simplemente no hay registro. No hay en absoluto presencia de esa normativa ontológica de la existencia civil que hace que haya cuerpos que importan.

Esta situación, que podría ser vivida y reivindicada como propia de una vida que se pretenda libre de sujeción, autónoma, conviene mejor leerla en clave de precariedad y desprotección. Es el caso de Jennifer, presidenta de una fundación de Ciudad de México dedicada a fomentar el registro de esa población que no es tal, que vive en el país, pero no consta. A Jennifer le inquieta los que quedan fuera de las cuentas del Estado, de sus registros más básicos, el documento oficial de identificación y el acta de nacimiento, que en México o no existen o no son obligatorios. Esto parece apuntar a una desaparición que es consustancial a México, dice que, según sus cuentas, siete millones de mexicanos no están registrados y por tanto no tienen derechos y son, desde eso, pasto de los mayores males: desaparición, trata, adopciones ilegales, trabajo esclavo. Es una masa de vulnerabilidades la que parece esconderse y hace a un elemento estructural en el país. Esta situación converge con una nota general del campo: si las desapariciones originarias afectaban a ciudadanos, las más recientes se inscriben en el reino de las poblaciones vulnerables, inexistentes, invisibles, sin derechos, ausentes. No es algo exclusivo de este país realmente, y cruza América de norte a sur, afectando a poblaciones a las que cada tanto las políticas civilizatorias de los gobiernos progresistas de turno procuran identificar -literalmente: censar, documentar, escolarizar, hospitalizar- para "hacerlos aparecer» en el Estado y en la ciudadanía (Gatti 2008). Pero siempre, siempre queda gente fuera: "Soy de esa gente que no tiene papeles, pues. Nunca tuve un acta de nacimiento. 0 sea, como si fuera un animal» (Martínez 2018: 87).

A esas poblaciones de no ciudadanos (Chatterjee 2008) parece corresponderles la denominación de Orlando Patterson (1982), que propuso el concepto de «muerte social» trabajando sobre la esclavitud. Es una forma de existencia invisibilizada, sometida a abandono, expulsada de los cuadros normativos co- munes. Es de eso de lo que creemos que aquí se trata, de vidas y cuerpos de los que "se puede disponer», de las que "se apoderan», en expresión de Daniela, la abogada que sigue los casos de «las desapariciones más desaparecidas», las de los migrantes que cruzan México de punta a punta. Son personas que «envidiarían el cuido que reciben nuestras mascotas» (Martínez 2018: 7), que, por no existir, no existen ni como desaparecidos.

La ruta de los migrantes centroamericanos está punteada de albergues. Algunos dicen que son más de treinta, pero su número va creciendo aquí y allá, día con día, siguiendo esas rutas que son también variables ${ }^{12}$. Recogen migrantes centroamericanos de paso hacia los Estados Unidos, o a los que de allí vienen deportados. Los hay también mexicanos, pero tampoco está claro porque la única prueba de su existencia son sus cuerpos. No hay nombres que se les asocien oficialmente a ellos. Pudimos ver un poco de los de Saltillo, Monterrey, Guadalajara, Palenque o Tenosique, apenas una muestra, todos o casi todos asociados a la Iglesia, que despliega aquí este entramado de instituciones con argumentos que recuerdan sin mucho esfuerzo a los de las misiones jesuíticas o los hospicios medievales. En el de Saltillo estaba el padre Jurado, conocido y reconocido en el mundo de la asistencia a los migrantes. Jurado aporta el componente de carisma al frondoso entramado de la economía moral humanitaria (Fassin 2010) que se desarrolla alrededor del asunto. Su discurso es contundente, pronunciado en los términos de la imaginería teológica: el bien, el mal. Aquí «la vida no vale», agrega. El relato está punteado de cuentas -72 de San Fernando en el 2010, 193 de Tamaulipas en 2011, 49 de Cadereyta en 2012-. Aturde. «Esto es el infierno», dice. $Y$ parece tener razón: frente a un mundo sin medidas, de puro abandono, los albergues ofrecen aquello que el Estado no da, protección, identidad, aunque sea hacia su interior y para el corto tiempo que dura la estancia de los migrantes allí. Parecen lugares de aparición para unos individuos que, aunque están vivos, han desaparecido de la sociedad, están fuera de su registro. Aquí, sí, la desaparición excede su capacidad de significar el crimen sobre un individuo-ciudadano; se acerca más a designar un

12 No hay un registro oficial de albergues para migrantes en México, pero algunos de ellos, auspiciados por el Servicio Jesuita a Migrantes de México, integran la Red de Documentación de las Organizaciones Defensoras de Migrantes: un total de 23 en 2016 (REDODEM 2017). 
asunto de gran alcance, que tiene envergadura de cuestión.

Llegando a México (junio de 2017), en el avión que le aproxima al país, uno de nosotros lee un documento que le envía el otro -el más local- como para ponerle en clima de campo. Quiere -dice- abrir el plano lo máximo posible, obturar un «gran angular» de máxima visión y poco detalle. El texto se llama «La cuestión desaparecida» y contiene esto:

En México, podemos hablar hoy de una «cuestión desaparecida». Como aquella que se dijo "social» en su momento, la «desaparecida» muestra las consecuencias de un orden social y político presente que se proyectan sobre otro futuro. Si en aquella este era el (des)orden industrial y el resultado de la pobreza, en esta es hoy el desorden en la administración de la violencia y la consecuencia de la desaparición como una categoría y una experiencia aglutinadora de otras manifestaciones y experiencias de violencia sobre el cuerpo social e individual. Se está transitando a la conformación de un conglomerado de significaciones comunes que remiten a valores centrales del pacto social. La cuestión desaparecida parece tomar la forma de "cuestión», en efecto, de problema de discusión general, de «aporía fundamental» (Castel 1997) del presente mexicano. Es su «hecho social total» (Mauss 2009).

Catorce meses después de esa primera aproximación al campo, en noviembre de 2018, tomamos parte de un hecho que los participantes califican de histórico, fundacional, larvario, la I Cumbre Mundial de Madres de Migrantes Desaparecidos. También a nosotros nos lo parece. Aunque desarrollado en México, recibe delegaciones de Túnez, Marruecos, El Salvador, Guatemala, Nicaragua, Honduras, Mauritania o Senegal, todas con la mochila llena, repleta, de historias espeluznantes: travesías de desiertos y de mares, torturas sistemáticas, trenes, centros de reclusión, invisibilidad, trata y más trata, esclavitud, deshumanización. Todo eso encuentra en desaparecido y desaparición ya sí sin la «maldita palabra» forzado o forzada detrás, un denominador común, algo que habilita el diálogo y el contacto y la mirada cómplice entre indígenas guatemaltecas, habitantes del Sahel, gentes del Atlas o madres de muchachos que huyeron de la M18 en El Salvador y de los que nunca se supo. Coinciden en México, y dialogan fuerte, con otras muchas madres y familiares ya no de migrantes pero sí de desaparecidos de los de ahora, gente de Guerrero, de Chiapas, de Tabasco, de Baja California, de Tamaulipas. De todo el país. No hay, eso no, quien represente a las viejas desapariciones, las originarias, al menos no a las de México o a las mesoamericanas, aunque sí aparece al final la sombra protectora del Aleph de las desapariciones en forma de mensaje afectuoso de una veterana Madre de Plaza de Mayo, que alienta a seguir por un camino que ella ya conoce y que las que están aquí congregadas aún no mucho.

Desde nuestra primera aproximación el campo ha cuajado, aunque sigue revuelto y movedizo. La categoría desaparecido aterrizó y congrega. Es un territorio de convergencia, no de disputa: ninguna niega a las otras la legitimidad de hacer uso de ella para definirse. Al contrario: en una suerte de ordalía asamblearia al grupo se agregan formas y formas de desaparición y en el final, optimista como suele ser en estos momentos fundacionales, la delegación mexicana y las de los migrantes tejen sus alianzas, acuerdan buscar a sus desaparecidos, ya de todos, para hacerlos existir, y se comprometen a acompañar mutuamente sus muchos caminares: unas en caravana de madres de migrantes desaparecidos, otras en las brigadas de búsqueda de restos de desaparecidos los que se presumen muertos- y aquellas en la caravana de búsqueda en vida de los desaparecidos que se cree puedan estar vivos, sin nombre ni registro, en penales $u$ hospitales del Estado o en casas de seguridad o campos de esclavos del narco o en burdeles de la frontera.

Se funden en un abrazo; fundan el campo.

\section{BIBLIOGRAFÍA CITADA}

Amnistía Internacional. 2016. «Un trato de indolencia». La respuesta del Estado frente a la desaparición de personas en México. Ciudad de México: Oficina Regional de Amnistía Internacional para las Américas.

Anderson, Benedict. 1992. Imagined Communities. Londres: Verso.

Anstett, Elisabeth. 2017. «Comparación no es razón: a propósito de la exportación de las nociones de desaparición forzada y detenidos-desaparecidos», en Gabriel Gatti, Desapariciones. Usos locales, circulaciones globales: 33-52. Bogotá: Siglo del Hombre.

Arendt, Hanna. 2004. Los orígenes de totalitarismo. Madrid: Taurus

Boltanski, Luc. 2016. Enigmas y complots. Una investigación sobre las investigaciones. Ciudad de México: Fondo de Cultura Económica.

Bourdieu, Pierre. 1991. El sentido práctico. Madrid: Taurus. 
Butler, Judith. 2017. Cuerpos aliados y lucha política: hacia una teoría performativa de la asamblea. Barcelona: Paidós.

Butler, Judith y Gayatri Spivak. 2009. ¿Quién le canta al Estadonación? Lenguaje, política, pertenencia. Buenos Aires: Paidós.

Calveiro, Pilar. 2006. Poder y desaparición. Buenos Aires: Colihué.

Castel, Robert. 1997. La metamorfosis de la cuestión social. Buenos Aires: Paidós.

Centro Diocesano para los Derechos Humanos Juan Fray de Larios. 2017. Diagnóstico del Registro Nacional de Datos de Personas Extraviadas o Desaparecidas (RNPED). Saltillo: Centro Diocesano para los Derechos Humanos Juan Fray de Larios. Disponible en: <http://www.frayjuandelarios.org/ blog/wp-content/uploads/2018/06/Libro-DH-corregidoabr_3_2018_1.pdf>. Fecha de acceso: 10 abr. 2019.

Chatterjee, Partha. 2008. La nación en tiempo heterogéneo y otros estudios subalternos. Buenos Aires: Siglo XXI.

Cowan, Jane. 2010. «Cultura y derechos después de Culture and Rights». Revista de Antropología Social 19: 67-101.

Diéguez, lleana. 2016. Cuerpos sin duelo: iconografías y teatralidades del dolor. Monterrey: Universidad Autónoma de Nuevo León.

Edkins, Jenny. 2011. Missing: Persons and Politics. Ithaca: Cornell University Press.

Fassin, Didier. 2010. La raison humanitaire. París: Gallimard.

Ferrándiz, Francisco y Antonius C. G. M. Robben. 2015. Necropolitics: Mass Graves and Exhumations in the Age of Human Rights. Filadelfia: University of Pennsylvania Press.

FLACSO. 2017. Informe sobre Desapariciones en el Estado de Nuevo León con información de CADHAC. Ciudad de México: FLACSO.

Foucault, Michel. 1997. Las palabras y las cosas. Una arqueología de las ciencias humanas. Madrid: Siglo XXI.

Gatti, Gabriel. 2008. El detenido-desaparecido. Narrativas posibles para una catástrofe de la identidad. Montevideo: Trilce.

Gatti, Gabriel. 2017. «Prolegómeno. Para una categoría científica de desaparición», en Gabriel Gatti, Desapariciones. Usos locales, circulaciones globales: 13-32. Bogotá: Siglo del Hombre.

González Villareal, Roberto. 2012. Historia de la desaparición. Nacimiento de una tecnología represiva. Ciudad de México: Terracota.

Huffschmid, Anne. 2015. "Huesos y humanidad. Antropología forense y su constitución ante la desaparición forzada». Athenea Digital 15(3): 195-214.
Irazuzta, Ignacio. 2017. «Aparecer desaparecidos en el norte de México. Las identidades de la búsqueda», en Gabriel Gatti, Desapariciones. Usos locales, circulaciones globales: 141-162. Bogotá: Siglo del Hombre.

Koselleck, Reinhardt. 2004. "Historia de los conceptos y conceptos de la historia». Ayer 53: 27-45.

Koselleck, Reinhardt. 2012. La historia de los conceptos. Estudios sobre semántica y pragmática del lenguaje político y social. Madrid: Trotta.

Mahlke, Kirsten. 2017. «Figuraciones fantásticas de la desaparición forzada», en Gabriel Gatti, Desapariciones. Usos locales, circulaciones globales: 75-98. Bogotá: Siglo del Hombre.

Marcus, Georges. 1995. «Ethnography in/on the World System. The Emergence of the Multi-Sited Ethnography». Annual Review of Anthropology 24: 95-117.

Martínez, Oscar. 2018. Los migrantes que no importan. Madrid: Pepitas de Calabaza.

Mauss, Marcel. 2009. Ensayo sobre el don. Buenos Aires: Katz.

Mayorga, Juan. 2017. El cartógrafo. Madrid: La Uña Rota.

Naciones Unidas-Comisión Nacional de Derechos Humanos. 2015. La desaparición forzada en México: una mirada desde los organismos del Sistema de Naciones Unidas. Ciudad de México.

Ngai, Mae. 2005. Impossible Subjects. Illegal Aliens and the Making of Modern America. Princeton: Princeton University Press.

Osorno, David E. 2017. Un vaquero cruza la frontera en silencio. Ciudad de México: Literatura Random House.

Patterson, Orlando. 1982. Slavery and Social Death. A Comparative Study. Cambridge, Massachusetts: Harvard University Press.

Periodistas de a Pie. 2017. "Buscadores». Pie de página. Disponible en: <https://piedepagina.mx/buscadores/index-. php>. Fecha de acceso: 5 nov. 2018.

Rancière, Jacques. 2009. El reparto de lo sensible. Estética y política. Santiago de Chile: LOM.

REDODEM. 2017. Migrantes en México: Recorriendo un camino de violencia. Informe 2016. Ciudad de México: Servicio Jesuita a Migrantes México.

Rousseaux, Fabiana. 2017. «Las víctimas del terror de Estado en el marco de las políticas públicas de reparación», en Gabriel Gatti, Un mundo de víctimas: 220-230. Barcelona: Anthropos.

Schindel, Estela. 2012. La desaparición a diario: sociedad, prensa y dictadura, 1975-1978. Villa María: Eduvim.

Weizman, Eyal. 2018. «Prólogo», en Forensic Architecture: 6-15. Barcelona: MACBA. 